\title{
THE ONTOGENY OF CHEMICALLY-MEDIATED ANTIPREDATOR BEHAVIOURS IN NEWTS (NOTOPHTHALMUS VIRIDESCENS): RESPONSES TO INJURED AND NON-INJURED CONSPECIFICS
}

\author{
by
}

\author{
JASON R. ROHR ${ }^{1,2)}$, DALE M. MADISON ${ }^{2)}$ and AARON M. SULLIVAN ${ }^{2,3)}$ \\ $\left({ }^{2}\right.$ Department of Biological Sciences, Binghamton University, State University of New \\ York, Binghamton, NY 13902-6000, USA)
}

(Acc. 9-VI-2002)

\begin{abstract}
Summary
Responses to alarm chemicals from injured prey may influence predation risk and foraging success of receivers and senders, while learning can influence the strength of these responses. Thus, it is important to know when in ontogeny prey produce and detect alarm substances and how learning shapes their response, but surprisingly little is known about either of these topics. We assessed when in the life of red-spotted newts, Notophthalmus viridescens, alarm chemicals are produced and detected by comparing adult versus eft (terrestrial juveniles) and larval responses to rinses and tissue extracts from individuals in each life-history stage. To evaluate the influence of experience in larvae exposed to conspecific alarm substances and rinses from adults known to cannibalize larvae, we compared the response of naïve larvae, which had no prior experience with alarm chemicals or predators, to experienced larvae, which were likely to have experienced alarm chemicals and predators in their native pond. Larvae were indifferent to larval rinses and extracts, but reduced their activity in response
\end{abstract}

1) Corresponding author's present address: 101 Morgan Building, University of Kentucky, Department of Biology, Lexington, KY 40506-0225, e-mail: jrohr@uky.edu

3) We thank David Calos, Dawn Cook, Jonathan Locitizer, Amy Picard, Ezequiel Rodriguez, and Eric Schipps for field and laboratory assistance, and Anne and Richard Bower for access to their pond. This study was licensed through the New York State Department of Environmental Conservation (LCP97-256, LCP98-427) and approved by the State University of New York at Binghamton (Institutional Animal Care and Use Committee, Protocol no. 406-98, 467-00). This work was supported in part by a grant from the National Science Foundation to DMM (IBN9974591), funds from the Department of Biological Sciences at the State University of New York at Binghamton, and a dissertation fellowship year from the graduate school at the State University of New York at Binghamton to JRR. 
to adult rinses and extracts. There was no difference between responses of recently hatched naïve and experienced larvae, indicating that larvae exhibit innate antipredator behaviors in response to adult odour. Adults were indifferent to all larval treatments and adult rinse, but avoided adult extract. Since neither adults nor larvae responded to larval extract, larvae did not appear to possess alarm chemicals, and consequently, we were unable to assess the influence of experience on alarm substance response in larvae. Adults and efts were indifferent to rinses, but avoided extracts from conspecifics of both life-history stages. Together, these results demonstrate that red-spotted newts do not produce alarm chemicals until late in larval development, but can respond to predation-related chemical cues soon after hatching.

\section{Introduction}

Aquatic and terrestrial prey use a variety of chemicals to evaluate the location and magnitude of predation threats (e.g. Chivers et al., 1997; Chivers \& Smith, 1998). Prey identify predation risk by detecting chemicals directly from potential predators (Kats \& Dill, 1998), from disturbed or distressed conspecifics, and from alarm chemicals released from injured conspecifics (Chivers \& Smith, 1998; Bryer et al., 2001). Numerous studies have demonstrated that prey can even learn to recognize predators by associating them with damage-release cues, suggesting that learned predator recognition by alarm chemical association has important implications for predator-prey interactions (e.g. Chivers \& Smith, 1994; Chivers et al., 1995a; Wisenden et al., 1997). Various factors can influence alarm cue responses, such as the state of prey (e.g. hunger-level, Smith, 1981; Brown \& Smith, 1996), or the context in which the cue is detected (e.g. season, Jacobsen \& Stabell, 1999).

Like responses to alarm substances, production of alarm chemicals can be context-dependent, and thus may not remain constant through the life of prey. Alarm cell production in fishes declines during breeding condition (Smith, 1973, 1992; Irving, 1996) and with familiar shoalmates (Wisenden \& Smith, 1998). Since production and maintenance of alarm substance may be costly (Wisenden \& Smith, 1997), and the benefit to the producer may not always be clear (Smith, 1992; Magurran et al., 1996; Henderson et al., 1997), prey at certain developmental stages may profit more from using alarm substance resources elsewhere, such as in growth. Many have argued that induced antipredator traits should be selected over innate traits in environments with varying predation risk (Via \& Lande, 1985; Moran, 1992), and thus, it may only pay to develop alarm chemicals after birth or hatching in environments with a high predation risk (induced alarm chemical production). 
While there is good reason to believe that prey may not hatch or be born with alarm substances or the ability to respond to them, there are also good reasons for production and detection of alarm substances to be innate. Intuitively, most antipredator behaviours are often assumed to be inherited, due to the life-threatening costs of not having appropriate antipredator adaptation s upon first encountering predators (Magurran, 1999). For example, cyprinid fishes respond to conspecific alarm substances without prior experience (Chivers et al., 1995b). It has also been suggested that detection of damage-release chemicals may be inherent because alarm chemicals facilitate learned predator recognition (Göz, 1941). It is also possible that alarm substance detection is innate while production is not, or vice versa, since the two events may become beneficial at different developmental ages. Experience plays an important role in refining even genetically-determine d antipredator reactions (see e.g. in Magurran, 1999), making it possible that learning can influence alarm substance responses even if they are innate.

Although the ontogeny of alarm substance production and response is relatively well understood in ostariophysan fishes (Pfeiffer, 1963, 1974; Waldman, 1982; Smith, 1992), only one study has addressed the ontogeny of production and detection in amphibians (Chivers et al., 1999), despite the importance of this knowledge to understanding amphibian population dynamics. The red-spotted newt (Notophthalmus viridescens) is an ideal amphibian to investigate the ontogeny of alarm chemical production and detection, and the influence of learning on alarm substance response. The species has two metamorphoses, one from the aquatic larva to terrestrial eft, and a second into the aquatic adult (Petranka, 1998), providing obvious developmental markers by which all individuals can be compared. Additionally, their shifts between habitats likely expose them to different predation pressures, which could influence both alarm substance production and response at least twice during their life history. Adult red-spotted newts are known to avoid injured conspecific adults (Woody \& Mathis, 1997; Rohr \& Madison, 2001), but not injured heterospecifics (Marvin and Hutchison, 1995). However, whether efts or larval newts possess and/or respond to conspecific alarm chemicals is not known. Finally, newts are capable of chemically-mediated associative learning (Woody \& Mathis, 1998), showing potential for experience to influence the alarm response. 
Since responses of adult newts to conspecific alarm substance are well understood (Woody \& Mathis, 1997; Rohr \& Madison, 2001), and since their amphibious lifestyle allows them to be tested in both aquatic and terrestrial environments (Marvin \& Hutchison, 1995; Rohr \& Madison, 2001), we used the adult response as a standard of comparison to determine whether the strictly aquatic larvae and/or strictly terrestrial efts produce and respond to conspecific alarm substance. We compared eft and adult responses to rinses and macerates of their own and the other's life-history stages in the laboratory using 'terrestrial' testing procedures, while larvae were similarly compared to the adults using 'aquatic' testing procedures. To evaluate whether experience influences the behaviour of larvae, we compared the responses of recently laboratory-hatched larvae, which had not experienced injured conspecifics or adults known to cannibalize larvae (Petranka, 1998), to field-caught larvae, which likely had experienced alarm substances and adult cannibalis $m$ in their native pond.

We hypothesized that test larvae would not produce alarm chemicals, because the early energy needs for growth likely take precedence to generating defensive products, and because alarm cell development of ostariophysan fishes does not occur until late in the ontogeny of juveniles (Smith, 1992). However, due to the importance of perceiving chemical cues for feeding and predator avoidance in turbid aquatic environments (Dodson et al., 1994), we predicted that larvae would be able to detect predation-related chemical cues, such as alarm substances. We anticipated that adult extract would elicit avoidance by both experienced and naïve larvae, but since experience increases the strength of alarm chemical avoidance in fishes (Chivers et al., 1995b), we expected experienced larvae to avoid alarm substance more than naïve larvae. Adult rinse was expected to induce innate antipredator responses in larvae because naïve larvae of California newts, Taricha torosa, exhibit antipredator behaviours in response to cannibalistic adults soon after hatching (Kats et al., 1994). Alternatively, adults were expected to be attracted to larval rinse as a potential food source, while efts and adults would be indifferent to rinses of their own and the other's life-history stage. However, efts and adults were expected to avoid eft and adult extract because of shared predators (Hurlbert, 1970). 


\section{Eft and adult newt responses in terrestrial test apparatuses}

\section{Collection and maintenance of animals}

Adult male newts were collected (when numerous) in May 2000 during the breeding season from a private pond in Chenango County, New York, USA, but were not used in tests until out of breeding condition in September 2000. In the interim, $\leqslant 15$ males were held in 38 litre aquaria containing aged tap water and simulated vegetation, were maintained at $18^{\circ} \mathrm{C}$ on a 14 : $10 \mathrm{hr}$ light : dark cycle, and were fed a liberal diet of chopped earthworms and freezedried bloodworms. Two days prior to trials, male newts were placed into separate, labelled, 0.47 litre plastic containers filled with aged tap water in the same controlled environment chamber as the aquaria. Individuals were returned to their plastic containers after each trial, allowing individual identification throughout the experiment.

Approximately 100 larval newts were collected in August 2000 from the same population as the adults. Larvae were placed into a 64 litre aquarium containing dechlorinated tap water and simulated vegetation, and the aquarium was inside a 567 litre cattle trough filled with $2 \mathrm{~cm}$ of dechlorinated tap water. Larvae were maintained in the same controlled environment chamber as the adult newts, and were fed freeze-dried brine shrimp and blood worms ad libitum. Each morning we gathered metamorphosed larvae that crawled out of the aquarium and fell into the cattle trough, and we placed these efts into 32 litre aquaria (in the same controlled environment chamber) containing paper towels for cover. No more than 30 efts were held per aquaria. Efts were fed flightless Drosophila ad libitum and their tanks were thoroughly misted daily. Two days prior to trials, 54 efts were transferred to individual, labelled, $9 \mathrm{~cm}$ (diameter) petri dishes containing a piece of moist paper towel, and each dish was thoroughly misted daily. As with the adults, individuals were returned to their assigned dish after each trial to facilitate individual identification during the experiment.

\section{Collection of rinses and extracts}

To obtain rinse from efts, 20 metamorphic efts with gill remnants were placed into $500 \mathrm{ml}$ of dechlorinated tap water for 48 hrs. This water was then filtered through glass wool, and equal numbers of $12 \mathrm{ml}$ aliquots (for eft trials; smaller test apparatuses required smaller test samples) and $17 \mathrm{ml}$ aliquots (for adult trials) were immediately frozen. To acquire alarm chemicals from efts, the efts used to obtain rinse were decapitated, their bodies were macerated in $500 \mathrm{ml}$ of dechlorinated tap water, the resulting solution was filtered through glass wool, and then equal numbers of 12 and $17 \mathrm{ml}$ aliquots were immediately frozen. Rinse and extracts from two adult male newts were obtained in the same manner, using the same volume of water. Rinses of non-injured conspecifics were used to control for conspecific chemicals unrelated to injury. Control water was handled, divided, and frozen like all other treatments, and treatments were thawed just before trials. Latex gloves were used for all stages of treatment and trial preparation to minimize treatment contamination.

\section{Experimental design and analysis}

We tested eft and adult responses to treatments using a 'terrestrial' petri dish design. For adults, the bottoms of fifty $15 \mathrm{~cm}$ diameter $(1.5 \mathrm{~cm}$ high) petri dishes received two semicircles of filter paper separated by a $3 \mathrm{~mm}$ gap that prevented fluids from mixing between 
halves. One semi-circle in each dish received $1.5 \mathrm{ml}$ of control water, and the other semi-circle received $1.5 \mathrm{ml}$ of adult extract, eft extract, adult rinse, eft rinse, or control water. A similar procedure was used for efts with some exceptions. First, $9 \mathrm{~cm}(1.5 \mathrm{~cm}$ high) rather $15 \mathrm{~cm}$ test dishes were used because efts are smaller that adults. Second, the smaller dishes required only $1 \mathrm{ml}$ rather than $1.5 \mathrm{ml}$ of treatment for each semi-circle. Third, unlike the adults, efts frequently adhered to the walls of test dishes, avoiding treatments if the filter paper was only placed on the bottom of the dish. So, moistened filter paper semi-circles $(11 \mathrm{~cm}$ diameter) were pressed along the bottom and sides of all test dishes. Finally, 55 rather than 50 animals were tested in a trial.

Petri dishes were randomly positioned and oriented (right or left) on a grid placed on the floor of a test room. Individuals were removed from their holding container, blotted free of excess water, placed in the center of their randomly assigned test dish, and the lid was returned to the dish. Lights were turned off, and infrared videotaping commenced for 100 minutes. All tests began between 1400 and $1530 \mathrm{hrs}$ in September of 2000, one day was provided between trials, and individuals were exposed to each treatment once in random order.

Like Marvin \& Hutchison (1995), we provided 20 minutes of acclimation to the petri dish, which seemed to provide sufficient time for the newts to return to pre-handling activity. We then recorded the side that each eft and adult occupied every two minutes for the next 80 minutes. If efts or adults straddled the gap between semi-circles, the side their snout occupied was recorded (Marvin \& Hutchison, 1995). Treatment 'avoidance' was recorded if $\geqslant 21$ of 41 positions were on the control side. Chi-square goodness-of-fit tests were used to determine preference for treatment or control substrates, and chi-square tests of independence were used to compare responses to rinses and extracts and to adult and eft treatments (Siegel \& Castellan, 1988).

\section{Results}

Adults and efts were indifferent to rinses, but each avoided extracts from adults and efts (Table 1). There was significantly greater avoidance of extracts than rinses for both efts $\left(\chi_{1}^{2}=23.69, p<0.001\right)$ and adults $\left(\chi_{1}^{2}=21.57, p<0.001\right)$, and no significant difference between eft and adult responses to extracts $\left(\chi_{1}^{2}=0.28, p=0.595\right)$ or rinses $\left(\chi_{1}^{2}=0.17\right.$, $p=0.683)$.

\section{Larval and adult newt responses in aquatic test apparatuses}

\section{Collection and maintenance of animals}

Collection and maintenance of adult male newts was identical to that previously described, except that it occurred in 2001 rather than 2000. Forty males were transferred to separate, labelled, 0.47 litre plastic containers filled with aged tap water two days before trials commenced, and were returned to these containers after each trial.

Larvae were obtained as naïve or experienced individuals. Naïve larvae were attained by allowing ten inseminated females (collected at the same time as the males and maintained in 
TABLE 1. Percent of efts and adults avoiding eft and adult rinses and extracts, and the associated statistical values

\begin{tabular}{lcccccrrr}
\hline Treatment & \multicolumn{3}{c}{ Eft response } & & \multicolumn{3}{c}{ Adult response } \\
\cline { 2 - 4 } & $\%$ avoiding & $\chi^{2}$ & $p$ & & $\%$ avoiding & $\chi^{2}$ & \multicolumn{1}{c}{$p$} \\
\hline Eft extract & 76 & 15.291 & $<0.001$ & & 84 & 23.120 & $<0.001$ \\
Eft rinse & 42 & 1.473 & 0.225 & & 52 & 0.080 & 0.777 \\
Adult extract & 82 & 22.273 & $<0.001$ & & 80 & 18.000 & $<0.001$ \\
Adult rinse & 55 & 0.455 & 0.500 & & 50 & 0.000 & 1.000 \\
\hline
\end{tabular}

a similar fashion) to oviposit in the laboratory. Once females appeared to cease oviposition, they were returned to the field. The aquarium containing only eggs and simulated vegetation was occasionally checked for newly hatched larvae, which appeared approximately six weeks later. These larvae will be referred to as 'naïve' larvae because they did not have prior experience with potential predators, including adult newts, or with damage-release cues. Furthermore, there was no contact with experienced conspecifics after hatching, preventing any culturally transmitted alarm substance or predator recognition (Suboski et al., 1990; Mathis et al., 1996).

A total of 100 'experienced' larvae, so named because they were captured from the field where they would be exposed to predators, were collected in June 2001 from the same population as the adults and maintained as described for the naïve larvae. Due to the natural abundance of adult and larval newts and the frequent attacks on larvae by many predators and ectoparasites (e.g. Mock \& Gill, 1984; Kessler \& Munns, 1991; Petranka, 1998), we felt that it was safe to assume that most field caught larvae would have been exposed to intraspecific adult predators and conspecific alarm chemicals (if possessed by larvae) prior to capture. Naïve larvae were tested at one- to two-weeks of age, and experienced larvae were estimated to be between two- and four-weeks of age.

Like adults, two days prior to trials, 17 naïve and 23 experienced larvae were transferred to separate, labelled 0.47 litre, plastic containers filled with aged tap water and kept in the same controlled environment chamber as the holding aquaria. Individuals were returned to their assigned container after each trial to facilitate individual identification during the experiment.

\section{Collection of rinses and extracts}

Rinses and extracts were obtained as described above with a few exceptions. Since macerate of 20 efts resulted in avoidance, and larvae were about half the length of efts, 40 experienced larvae were used to obtain larval rinse and extract. Rinses and macerates were obtained using $250 \mathrm{ml}$ of dechlorinated water, and equal numbers of 5 (for larval trials) and 17 (for adult trials) $\mathrm{ml}$ aliquots were immediately frozen. There were five treatments total: adult extract, larval extract, adult rinse, larval rinse, and control water.

\section{Experimental design and analysis}

Larvae were tested between 0900 and $1100 \mathrm{hrs}$, on five consecutive days in June of 2001 using 40 plastic troughs $(29 \mathrm{~cm}$ length $\times 3.25 \mathrm{~cm}$ wide $\times 5 \mathrm{~cm}$ high). Each trough contained $100 \mathrm{ml}$ 
of dechlorinated tap water $\left(20^{\circ} \mathrm{C}\right)$, and was divided into $23(1.25 \mathrm{~cm})$ equal segments using permanent marker. Two plastic mesh gates enclosed larvae in the three central segments of their randomly assigned trough for a one $\mathrm{hr}$ acclimation period. Tuberculin syringes were then used to simultaneously inject one $\mathrm{ml}$ of the appropriate treatment and one $\mathrm{ml}$ of dechlorinated water into randomly chosen but opposite ends of the troughs. All larvae were exposed to each treatment once in random order over the five days. Gates were removed five minutes after treatment injection, and two observers, unaware of the treatments in the troughs, remained stationary on opposite ends of the troughs to record the numbered segment that each larva occupied every minute for 30 minutes. Activity was quantified by calculating the number of lines crossed between the current and previous one-minute positions. Each value was subsequently square root transformed before analysis. Once the experiment was complete, the length of each larva was recorded.

We used a repeated-measures multivariate analysis of covariance (MANCOVA), with length as the covariate, to evaluate the effects of independent factors, treatment (adult and larval rinses and extracts and control water) and experience (naïve or experienced), on the dependent variables, location (quadrant location relative to test solution) and activity (average number of segments crossed; Johnson \& Wichern, 1998). After MANCOVA, repeatedmeasures univariate analyses of covariance (ANCOVAs) were conducted on each dependent variable, and Tukey post-hoc multiple comparison tests were used where main effects of treatment occurred. Three larvae were outliers (leverage test) that greatly influenced the slope of the regression line for experienced larvae (DFFITS and DFBETAS tests, Neter $e$ t al., 1996). Consequently, we felt justified to remove these three larvae from our activity analyses.

Adult male newts were tested using the trough design described by Rohr \& Madison (2001), which was identical to the larval design with the exception that everything was scaled up to fit the larger adults. Ten test troughs consisted of white, U-shaped in cross section, 101 $\mathrm{cm}$-long gutters $(11.4 \mathrm{~cm}$ wide $\times 6.4 \mathrm{~cm}$ high $)$ sealed at both ends with plastic caps, divided into 20 equal subdivisions using permanent marker, and containing one litre of dechlorinated tap water at $20^{\circ} \mathrm{C}$. Rectangular release cages $(21 \mathrm{~cm}$ long $\times 7.6 \mathrm{~cm}$ wide $\times 6.4 \mathrm{~cm}$ high $)$ constructed from perforated plastic normally used for needlepoint ( $2 \mathrm{~mm}$ square holes), were centered into each trough, and contained each newt for the one hr acclimation period. The top and two longest sides of the cages were covered with grey tape to discourage climbing. Five $\mathrm{ml}$ of treatment and control water were simultaneously injected into opposite ends of the troughs, so that the volume of treatment per $\mathrm{ml}$ of water was identical to that used in larval trials. Release cages were lifted and removed from the troughs five minutes later, and a single stationary observer, unaware of treatment locations, recorded the numbered segment that each newt occupied every minute for thirty minutes. Trials were conducted between 1300 and 1500 hrs during 20 days of July 2001, and each newt was only exposed to each treatment once in a random order.

The numbered segment that each adult occupied was recorded every minute for thirty minutes. Activity was recorded as previously described. We used a repeated-measures MANOVA to evaluate the effects of treatment (adult and larval rinses and extracts and control water) on the dependent variables, location (quadrant location relative to test solution) and activity (average number of segments crossed; Johnson \& Wichern, 1998). After MANOVA, we used ANOVA on each response variable to interpret patterns uncovered by the MANOVA, and conducted Tukey post hoc multiple comparison tests where main effects of treatment occurred. 


\section{Results}

All experienced larvae were greater in length than naïve larvae, however the regression lines for the relationship between larval length and activity for experienced and naïve larvae were parallel and fit similar trajectories (excluding data from three outlying larvae; Fig. 1). The three outlying larvae suggest that larval behaviour may change at longer lengths. Larval length was significantly related to, and accounted for $24 \%$ of the variation in, larval activity $(R=0.49, p<0.001$, Fig. 1$)$. Increasing larval activity with increasing larval length was most likely an artifact of using the same size troughs and division s $(1.25 \mathrm{~cm})$ for larvae of various lengths.

For larvae, results of MANCOVA revealed no main effect of experience, but a main effect of treatment, while ANCOVA showed that the effect of treatment was significant for larval activity, but not for larval location (Table 2). Tukey multiple comparisons revealed that larvae were significantly less active when exposed to adult rinse and adult extract than control treatments, and that activity did not significantly differ between adult rinse and extract (Table 3, Fig. 2). Although larvae were more active when

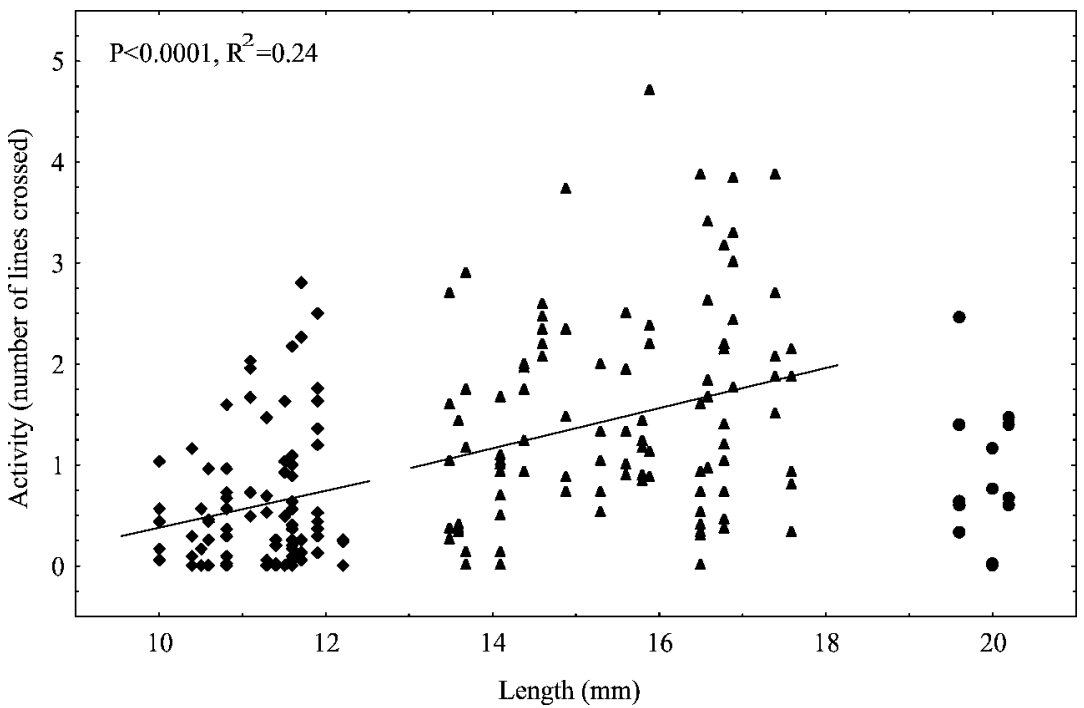

Fig. 1. Relationship between larval length and activity for naïve (diamonds) and experienced newt larvae (triangles). Three experienced larvae (represented by the 15 circles) were influential outliers, and were thus excluded from the analyses. Best-fit lines are provided for both naïve and experienced larval data, but the statistics provided are for the combination of naïve and larval data. 
TABLE 2. Results of repeated-measures MANCOVA, with larval length as a covariate, and subsequent repeated-measures ANCOVAs, for the effects of larval experience (naïve or experienced) and treatment (larval and adult rinses and extracts, and control water), on larval location and activity (a), and repeated-measures MANOVA, and subsequent ANOVAs, on adult location and activity responses to the same treatments $(b)$

\begin{tabular}{lccc}
\hline Effect & $d f$ & $F$ & $p$ \\
\hline (a) Larval response & & & \\
MANCOVA & & & \\
$\quad$ Experience & 2,33 & 0.577 & 0.567 \\
Treatment & 8,28 & 2.962 & 0.016 \\
Experience $\times$ treatment & 8,28 & 0.517 & 0.833
\end{tabular}

\section{ANCOVA}

Location

Experience

\section{1,34}

0.697

0.410

Treatment

4,140

0.728

0.574

Experience $\times$ treatment

4,140

0.336

0.853

ANCOVA

Activity

Experience

1,34

0.119

0.732

Treatment

4,140

3.566

0.008

Experience $\times$ treatment

4,140

0.847

0.498

(b) Adult response

MANOVA

Treatment

8,30

2.053

0.074

ANOVA

Location

Treatment

4,156

3.501

0.009

ANOVA

\section{Activity}

Treatment

4,148

1.258

0.289

Three outliers were removed from larval and adult data.

exposed to larval treatments than adult treatments (Fig. 2), activity did not significantly differ between larval and adult treatments (Table 3). The smaller naïve larvae appeared to reduce their activity in response to larval treatments more than the larger experienced larvae (Fig. 2), but this comparison was not significant. 
TABLE 3. Probability values associated with pairwise comparisons by Tukey test for larval activity $(a)$ and adult location $(b)$ in response to control water $(C W)$, larval extract $(L E)$, larval rinse $(L R)$, adult extract $(A E)$, and adult rinse $(A R)$

(a) Larval activity

$\begin{array}{lccccc} & \text { CW } & & & & \\ \text { CW } & 1.000 & \text { LE } & & & \\ \text { LE } & 0.871 & 1.000 & \text { LR } & & \\ \text { LR } & 0.703 & 0.998 & 1.000 & \text { AE } & \text { AR } \\ \text { AE } & 0.016 & 0.202 & 0.358 & 1.000 & 1.000 \\ \text { AR } & 0.025 & 0.265 & 0.444 & 1.000 & \end{array}$

(b) Adult location

\begin{tabular}{lccccc} 
& CW & & & & \\
CW & 1.000 & LE & & & \\
LE & 0.860 & 1.000 & LR & & \\
LR & 1.000 & 0.803 & 1.000 & AE & AR \\
AE & 0.039 & 0.358 & 0.028 & 1.000 & 1.000 \\
AR & 0.993 & 0.611 & 0.998 & 0.010 & \\
\hline
\end{tabular}

For adults, results of MANOVA showed a nearly significant main effect of treatment, and, in contrast to the larvae, ANOVA revealed that the effect of treatment was significant for location rather than activity (Table 2). Tukey multiple comparison test showed that adult males avoided adult extracts significantly more than all treatments except for larval extract (Table 3, Fig. 3).

\section{Discussion}

It is likely that efts and adult newts share predators while syntopic, providing a benefit to efts and adults to respond to alarm substances from their own and the other's life-history stages. There is evidence of considerable predation on efts and adult newts in the laboratory (Hurlbert, 1970) and field (Rohr \& Madison, 2002; Shure et al., 1989), despite the presence of a potent neurotoxin in efts and adults (tetrodotoxin, Brodie, 1968). Predators that preyed on newts in the laboratory often consumed both adults and efts (Hurlbert, 1970). Furthermore, many adult newts move to terrestrial habitats during late summer (Harris et al., 1988; Huheey \& Stupka, 1965; Hurlbert, 1969), where they coexist with efts (pers. obs.) and exhibit similar terrestrial 

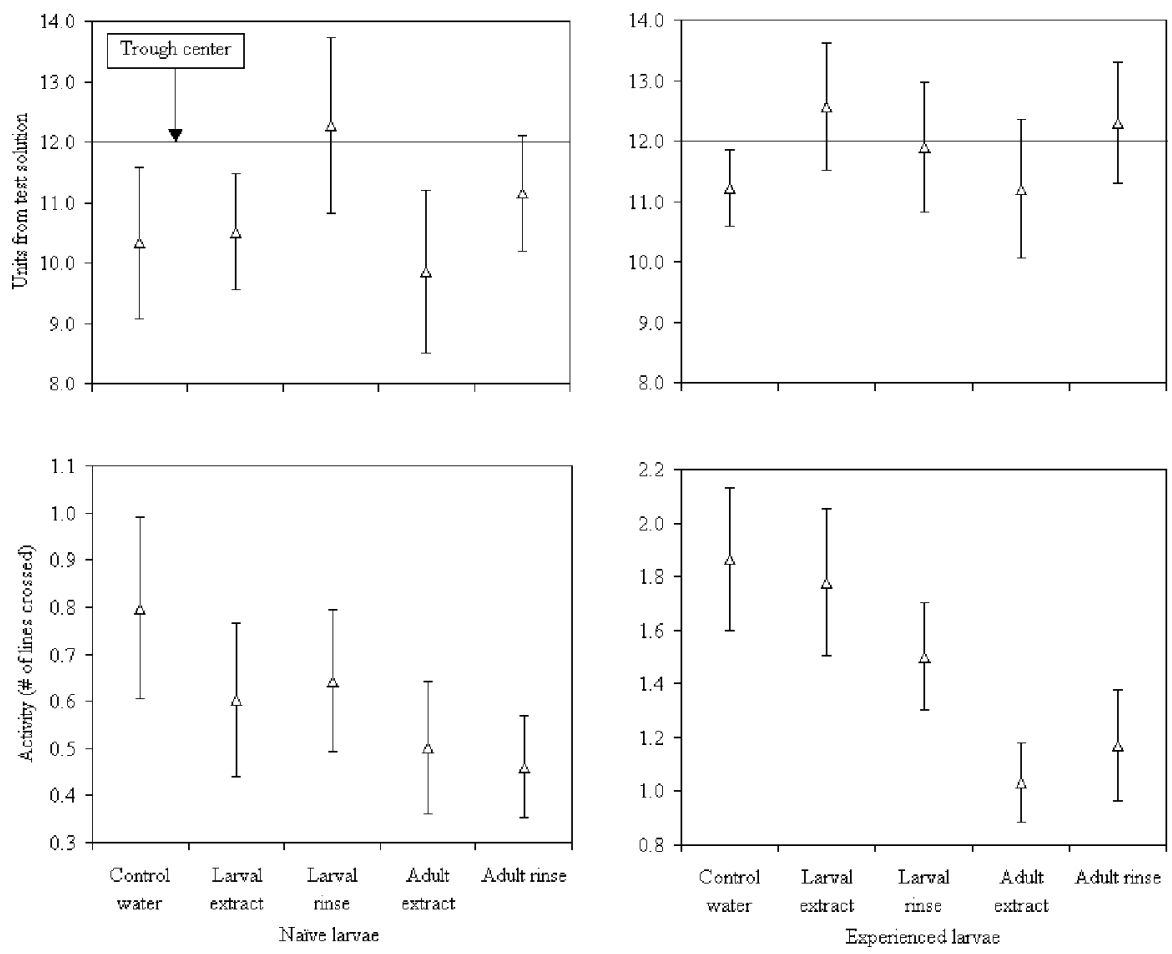

Fig. 2. Mean location and activity responses of naïve and experienced larval newts in response to control water, larval extract, larval rinse, adult extract, and adult rinse.

antipredator postures (Ducey \& Dulkiewicz, 1994). Retaining avoidance responses to conspecific alarm substances through metamorphosis, and across aquatic and terrestrial habitats, is consistent with the findings of Chivers et al. (1999) who demonstrated that Bufo boreas and Rana aurora continued to avoid conspecific alarm chemicals after metamorphosis and immigration into terrestrial habitats. The most parsimonious explanation for our data is that efts and adults produce the same alarm chemical that evolved to function in both aquatic and terrestrial environments.

In contrast to the similar responses of adults and efts, larvae reduced their activity while adults avoided adult extract, but this discrepancy is most likely due to the different scales in which the two were tested, rather than to inherent differences in their responses. Test solutions should diffuse across the entire length of the smaller larval troughs before diffusing across the entire length of the larger adult troughs, resulting in sooner breakdown 

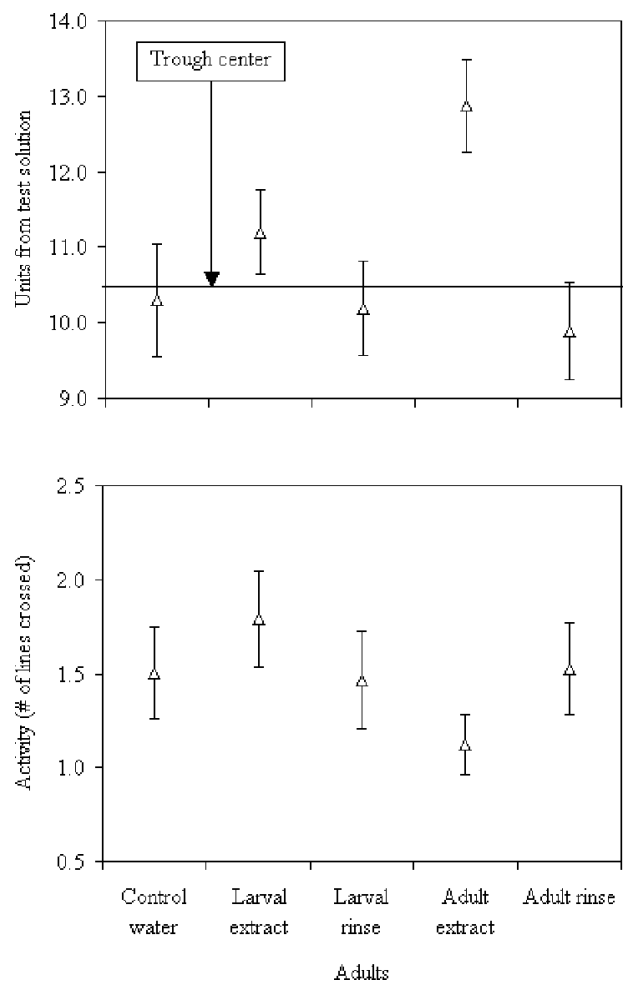

Fig. 3. Mean location and activity responses of adults newts in response to control water, larval extract, larval rinse, adult extract, and adult rinse.

of directional (gradient) information for test larvae than test adults. If larvae were surrounded by a uniform predation stimulus, and thus could not move down a concentration gradient, their secondary response may have been to reduce activity. Similar logic may explain why adults did not reduce their activity in response to adult extract, as in a previous study by Rohr \& Madison (2001). Rohr \& Madison (2001) used 3.5 litres of water in their troughs, which allowed for rapid swimming by adult newts. Swimming would increase the diffusion rate of the test substance, decreasing the reliability of directional information, and thus increasing the benefit of reduced activity. In our study, we only used one litre of water in troughs, which was just enough to submerge adults. Consequently, most adults slowly crawled rather than rapidly swam, likely conserving test solution gradients and resulting in only a significant avoidance response. 
Adults surprisingly were not attracted to larval rinse even though larvae are a food source for adult newts (Petranka, 1998). Adults cannot discriminate between their own and other's larvae (Gabor, 1996), and thus there may be an inclusive fitness cost discouraging cannibalism. However, adults were kept well fed, and it remains to be tested whether hunger would induce attraction to larval rinse.

Not surprisingly, larvae significantly reduced their activity in troughs containing rinse from adults capable of larval cannibalism (Petranka, 1998). Although newts can acquire recognition of predators through associative learning (Woody \& Mathis, 1998), our results indicate that a reduction in larval activity in response to adult rinse is innate because the response of recently hatched larvae that had, and had not, been exposed to adults and alarm substances did not significantly differ. These results are consistent with naïve (no experience with conspecific predators), two-week old California newt, T. torosa, larvae seeking refuge in response to adult cannibals (Elliot et al., 1993; Kats et al., 1994), and N. viridescens larvae reducing their activity in response to chemical cues from predatory Ambystoma tigrinum larvae (Mathis \& Vincent, 2000). Although not statistically significant, experienced larvae did appear to reduce activity in response to adult treatments more than did the naïve larvae, suggesting that learning may influence this innate antipredator response. Determining whether larvae respond specifically to adult alarm substances was not possible because the observed reduction in activity to adult macerate could be explained by a reduction in activity to adult rinse contained within the macerate.

Similar to adults, large larvae cannibalize smaller larvae posing a threat to some, but not all, larvae (Walters, 1975; Harris et al., 1988). This sizedependent cannibalism may explain the greater reduction in activity by the smaller naïve larvae to the larval rinses and macerates. However, unlike the response to the consistently ominous adults, larvae did not significantly reduce their activity in response to odour from the occasionally ominous larvae. This may be adaptive since reducing activity in response to all larvae may unnecessarily reduce foraging opportunitie s (Kats \& Dill, 1998).

Our data suggest that larval newts do not possess alarm chemicals soon after hatching, but begin producing alarm substance late in larval development, because neither adults nor early-stage larvae significantly responded to larval macerate, but macerate from recently metamorphosed efts elicited avoidance. This result is consistent with the development of alarm cells in 
ostariophysan fishes, which occurs late in the ontogeny of juveniles (Smith, 1992), and similar to the findings of Belden et al. (1998) who demonstrated that juvenile western toads, Bufo boreas, avoid chemical cues from snakes fed juvenile, but not larval (tadpoles), conspecifics. Newt alarm chemical production seems to correspond with the timing of newt poison gland production, which also begins late in larval development, providing further evidence that the larval life-history stage of newts is the most vulnerable to predation (Formanowicz \& Brodie, 1982; Mathis \& Vincent, 2000). Olfactory development, however, clearly precedes alarm chemical production since larvae responded to adult treatments. Dense vegetation and turbidity can make visual cues in aquatic habitats unreliable (Dodson et al., 1994), possibly rendering innate olfactory sensitivity necessary for larval foraging and predator avoidance.

Although our data support the production of alarm chemicals late in larval development, this result should be accepted with some caution. Since the terrestrial efts and aquatic larvae could not be tested under the same conditions, differences in response to, and production of, alarm chemicals could only be inferred rather than directly compared using factorial ANOVA. The power of tests comparing larval activity and adult location responses when exposed to control water and larval extract was only estimated at $20 \%$ for both dependent variables (Sokal \& Rohlf, 1998). It is possible that larvae possess trace amounts of alarm substance upon hatching, but the 40 larvae used to make the macerate did not produce a solution concentrated enough to detect a response in test newts. Chemical identification of alarm chemicals would facilitate examining and controlling for concentrations at various ontogenetic stages, and would greatly assist in pinpointing the timing of alarm substance production.

This is the first study in amphibians to assess when in ontogeny alarm chemicals are initially produced. Similar investigations on other species should help elucidate the magnitude of risk exposed to their various ontogenetic stages, and would help establish patterns in the timing of alarm substance development. Both induced alarm chemical production, and developmental or resource constraints should be examined as possible explanations for delayed alarm chemical production after birth or hatching. The influence of experience on alarm substance response could not be assessed in this study because naïve and experienced larvae did not appear to produce alarm chemicals, but avoided adult rinse and extract, and thus the importance of learning on conspecific alarm chemical responses remains equivocal. 


\section{References}

Belden, L.K., Wildy, E.L., Hatch, A.C. \& Blaustein, A.R. (1998). Juvenile western toads, Bufo boreas, avoid chemical cues of snakes fed juvenile, but not larval, conspecifics. Anim. Behav. 59, p. 871-875.

Brodie, E.D., Jr. (1968). Investigations of the skin toxin of the red spotted newt, Notophthalmus viridescens viridescens. - Am. Midl. Nat. 80, p. 276-280.

Brown, G.E. \& Smith R.J.F. (1996). Foraging trade-offs in fathead minnows (Pimephales promelas, Osteichthyes, Cyprinidae): acquired predator recognition in the absence of an alarm response. - Ethology 102, p. 776-785.

Bryer, P.J., Mirza, R.S. \& Chivers, D.P. (2001). Chemosensory assessment of predation risk by slimy sculpins (Cottus cognatus): responses to alarm, disturbance, and predator cues. - J. Chem. Ecol. 27, p. 533-546.

Chivers, D.P., Brown, G.E. \& Smith, R.J.F. (1995a). Acquired recognition of chemical stimuli from pike, Esox lucius, by brook stickleback, Culaea inconstans (Osteichthyes, Gasterosteidae). - Ethology 99, p. 234-242.

— —, Kiesecker, J.M., Wildy, E.L., Anderson, M.T. \& Blaustein, A.R. (1997). Chemical alarm signalling in terrestrial salamanders: intra- and interspecific responses. - Ethology 103 , p. 59-613.

— —, — — — - Belden, L.K., Kats, L.B. \& Blaustein, A.R. (1999). Avoidance response of post-metamorphic anurans to cues of injured conspecific and predators. - J. Herpetol. 33, p. 472-476.

— — \& Smith, R.J.F. (1994). Fathead minnows, Pimephales promelas, acquire predator recognition when alarm substance is associated with the sight of unfamiliar fish. Anim. Behav. 48, p. 597-605.

- — \& — - (1998). Chemical alarm signaling in aquatic predator-prey systems: a review and prospectus. - Écoscience 5, p. 338-352.

- - Wisenden, B.D. \& Smith, R.J.F. (1995b). The role of experience in the response of fathead minnows (Pimephales promelas) to skin extract of Iowa darters (Etheostoma exile). - Behaviour 132, p. 665-674.

Dodson, S.I., Crowl, T.A., Peckarsky, B.L., Kats, L.B., Covich, A.P. \& Culp, J.M. (1994). Nonvisual communication in freshwater benthos: an overview. - J. N. Am. Benthol. Soc. 13 , p. 268-282.

Ducey, P.K. \& Dulkiewicz, J. (1994). Ontogenetic variation in antipredator behaviour of the newt Notophthalmus viridescens: comparison of terrestrial adults and efts in field and laboratory tests. - J. Herpetol. 28, p. 530-533.

Elliot, S.A., Kats, L.B. \& Breeding, J.A. (1993). The use of conspecific chemical cues for cannibal avoidance in California newts (Taricha torosa). - Ethology 95, p. 186-192.

Formanowicz, D.R., Jr. \& Brodie, E.D., Jr. (1982). Relative palatabilities of members of a larval amphibian community. - Copeia 1982, p. 91-97.

Gabor, C.R. (1996). Differential kin discrimination by red-spotted newts (Notophthalmus viridescens) and smooth newts (Triturus vulgaris). - Ethology 102, p. 649-659.

Göz, H. (1941). Über den Art-und Individualgeruch bei Fischen. — Zeitschrift für vergleichende Physiologie 29, p. 1-45.

Harris, R.N., Alford, R.A. \& Wilbur, H.M. (1988). Density and phenology of Notophthalmus viridescens dorsalis in a natural pond. - Herpetologica 44, p. 234-242.

Henderson, P.A., Irving, P.W. \& Magurran, A.E. (1997). Fish pheromones and evolutionary enigmas: a reply to Smith. — Proc. R. Soc. Lond. B 264, p. 451-453. 
Huheey, J.E. \& Stupka, A. (1965). Herpetological records from the great Smoky Mountains. - Herpetologica 21, p. 148-150.

Hurlbert, S.H. (1969). The breeding migrations and interhabitat wandering of the vermilionspotted newt Notophthalmus viridescens (Rafinesque). — Ecol. Monogr. 39, p. 465-488.

- - (1970). Predator responses to the vermillion-spotted newt (Notophthalmus viridescens). - J. Herpetol. 4, p. 47-55.

Irving, P.W. (1996). Sexual dimorphism in club cell distribution in the European minnow and immunocompetence signalling. - J. Fish Biology 48, p. 80-88.

Jacobsen, H.P. \& Stabell, O.B. (1999). Predator-induced alarm responses in the common periwinkle, Littorina littorea: dependence on season, light conditions, and chemical labeling of predators. - Mar. Biol. 134, p. 551-557.

Johnson, R.A. \& Wichern, D.W. (1998). Applied multivariate statistical analyses, $4^{\text {th }}$ ed. Prentice Hall, Upper Saddle River, New Jersey.

Kats, L.B., Breeding, J.A. \& Hanson, K.M. (1994). Ontogenetic changes in California newts (Taricha torosa) in response to chemical cues from conspecific predators. - J. N. Am. Benthol. Soc. 13, p. 321-325.

— — \& Dill, L.M. (1998). The scent of death: chemosensory assessment of predation risk by prey animals. - Écoscience 5, p. 361-394.

Kessler, D.H. \& Munns, W.R., Jr. (1991). Diel feeding by adult red-spotted newts in the presence and absence of sunfish. - J. Freshw. Ecol. 6, p. 267-273.

Magurran, A.E (1999). The causes and consequences of geographic variation in antipredator behaviour: perspectives from fish populations. - In: Geographic variation in behaviour: perspectives on evolutionary mechanisms (S.A. Foster \& J.A. Endler, eds). Oxford University Press, New York, p. 139-163.

— - Irving, P.W. \& Henderson, P.A. (1996). Is there a fish alarm pheromone? A wild study and critique. - Proc. R. Soc. Lond. B 263, p. 1551-1556.

Marvin, G.A. \& Hutchison, V.H. (1995). Avoidance response by adult newts (Cynops Pyrrhogaster and Notophthalmus viridescens) to chemical alarm cues. - Behaviour 132, p. 95-105.

Mathis, A., Chivers, D.P. \& Smith, R.J.F. (1996). Cultural transmission of predator recognition in fishes: intraspecific and interspecific learning. - Anim. Behav. 51, p. 185-201.

- - \& Vincent, F. (2000). Differential use of visual and chemical cues in predator recognition and threat-sensitive predator-avoidance responses by larval newts (Notophthalmus viridescens). - Can. J. Zool. 78, p. 1646-1652.

Mock, B.A. \& Gill, D.E. (1984). Infrapopulation dynamics of trypanosomes in red-spotted newts. - Parasitology 88, p. 267-282.

Moran, N.A. (1992). The evolutionary maintenance of alternative phenotypes. - Amer. Nat. 139, p. 971-989.

Neter, J., Kutner, M.H., Nachtsheim, C.J. \& Wasserman, W. (1996). Applied Linear Statistical Models, $4^{\text {th }}$ ed. - WCB/McGraw-Hill, Boston, p. 375-384.

Petranka, J.W. (1998). Salamanders of the United States and Canada. - Smithsonian Institution Press, Washington, p. 451-462.

Pfeiffer, W. (1963). The fright reaction in North American fish. — Can. J. Zool. 41, p. 69-77.

- - (1974). Pheromones in fish and amphibians. - In: Pheromones (M.C. Birch, ed.). North-Holland, Amsterdam, p. 269-296.

Rohr, J.R. \& Madison, D.M. (2001). A chemically-mediated trade-off between predation risk and mate search in newts. - Anim. Behav. 62, p. 863-869. 
— — \& - - (2002). Notophthamlus viridescens (Eastern Red-Spotted Newt) Predation. Herpetol. Rev. 33, p. 122-123.

Shure, D.J., Wilson, L.A. \& Hochwender, C. (1989). Predation on aposematic efts of Notophthalmus viridescens. - J. Herpetol. 23, p. 437-439.

Siegel, S. \& Castellan, N.J., Jr. (1988). Nonparametric statistics for the behavioural sciences. - McGraw-Hill, Inc., New York.

Smith, R.J.F. (1973). Testosterone eliminates alarm substance in male fathead minnows. Can. J. Zool. 51, p. 875-876.

- - (1981). Effect of food deprivation on the reaction of Iowa darters (Etheostoma exile) to skin extract. - Can. J. Zool. 59, p. 558-560.

— - (1992). Alarm signals in fishes. - Rev. Fish Biol. Fish. 2, p. 33-63.

Sokal, R.R. \& Rohlf, F.J. (1998). Biometry: principles and practice of statistics in biological research, $3^{\text {rd }}$ ed. - W.H. Freeman and Company, New York.

Suboski, M.D., Bain, S., Carty, A.E., McQuoid, L.M., Seelen, M.I. \& Seifert, H. (1990). Alarm reaction in acquisition and social transmission of simulated-predator recognition by zebra danio fish (Brachydanio rerio). - J. Comp. Psychol. 104, p. 101-112.

Via, S. \& Lande, R. (1985). Genotype-environment interaction and the evolution of phenotypic plasticity. - Evolution 39, p. 502-522.

Waldman, B. (1982). Quantitative and developmental analyses of the alarm reaction in zebra danio, Brachydanio rerio. - Copeia 1982, p. 1-9.

Walters, B. (1975). Studies of interspecific predation within an amphibian community. J. Herpetol. 9, p. 267-279.

Wisenden, B.D., Chivers, D.P. \& Smith, R.J.F. (1997). Learned recognition of predation risk by Enallagma damselfly larvae (Odonata, Zygoptera) on the basis of chemical cues. J. Chem. Ecol. 23, p. 137-151.

— — \& Smith, R.J.F. (1997). The effect of physical condition and shoalmate familiarity on proliferation of alarm substance cells in the epidermis of fathead minnows. - J. Fish Biol. 50, p. 799-808.

- — \& - (1998). A re-evaluation of the effect of shoalmate familiarity on the proliferation of alarm substance cells in ostariophysan fishes. - J. Fish Biol. 53, p. 841846.

Woody, D.R. \& Mathis, A. (1997). Avoidance of areas labelled with chemical stimuli from damaged conspecifics by adult newts, Notophthalmus viridescens, in a natural habitat. - J. Herpetol. 31, p. 316-318.

— — \& - - (1998). Acquired recognition of chemical stimuli from an unfamiliar predator: associative learning by adult newts, Notophthalmus viridescens. - Copeia 1998, p. $1027-1031$. 
Copyright $\odot 2002$ EBSCO Publishing 